\title{
veterinary sciences
}

ISSN 2306-7381

www.mdpi.com/journal/vetsci

Review

\section{Respiratory Animal Models in the Common Marmoset (Callithrix jacchus)}

\section{Christoph Curths ${ }^{1,2}$, Sascha Knauf ${ }^{1,2}$ and Franz-Josef Kaup ${ }^{1, *}$}

1 Pathology Unit, German Primate Center, Leibniz-Institute for Primate Research, Kellnerweg 4, 37077 Göttingen, Germany

2 Department of Airway Immunology, Fraunhofer Institute for Toxicology and Experimental Medicine, Biomedical Research in Endstage and Obstructive Lung Disease Hannover (BREATH), Member of the German Center for Lung Research, Nikolai-Fuchs-Strasse 1, 30625 Hannover, Germany; E-Mails: ccurths@dpz.eu (C.C.); sknauf@dpz.eu (S.K.)

* Author to whom correspondence should be addressed; E-Mail: fkaup@gwdg.de; Tel.: +49-551-3851-241; Fax: +49-551-3851-442.

Received: 23 April 2014; in revised form: 6 June 2014 / Accepted: 10 June 2014 / Published: 20 June 2014

\begin{abstract}
Common marmosets (Callithrix jacchus) are small non-human primates (NHPs) that are often used for respiratory research. Translational animal models of various pulmonary diseases in marmosets have been developed in favor of models in old world monkeys (OWM, e.g., rhesus or cynomolgus monkeys). The marmoset has the size of a rat (350-450 g), is easier to handle, and the husbandry, care, and management of colonies is much easier compared to OWMs. In contrast to rodents, marmosets provide a high homology to humans, which become especially visible in lung architecture and branching pattern. Features of inflammatory (e.g., COPD) pulmonary diseases can be modeled in marmosets as well the species is used to study bacterial and viral infection. Models for human melioidosis, tuberculosis, anthrax, as well as infections with SARS-associated coronavirus (SARS-CoV), influenza A virus and adenovirus are already established. Toxicological studies often use marmoset monkeys for the advantage of immunological identical twins that are produced by a Callitrichinae-specific placentation type, which ultimately causes blood chimerism. Relatively new approaches in gene therapy use marmosets for respiratory disease research. In this review we will give an overview of existing respiratory marmoset models and their impact on biomedical research.
\end{abstract}


Keywords: marmoset; non-human primate; animal models; respiratory diseases

\section{Introduction}

The common marmoset (Callithrix jacchus) is a New World primate, native to northeastern Brazil and belongs to the family of the Callitrichidae. The species has several advantages when compared to Old World monkeys (OWM, e.g., rhesus (Macaca mulatta) or cynomolgus monkeys (M. fascicularis)). Its low body weight (350-450 g), for example, is comparable to the size of a rat (Figure 1) and makes marmosets an easy to handle and economically attractive NHP species for biomedical research $[1,2]$. Early sexual maturity and high reproductive efficacy allow fast breading capacities and therefore animal supply [3]. Due to hematopoietic chimerism, marmosets but not OWMs, give birth to immunologically identical twins, which facilitates matched control study designs [4]. The absence of herpes virus B (Macacine herpesvirus 1) in new world monkeys (NWMs), a virus that is highly lethal to man and commonly found in Asiatic macaques [2,5], contributes to a relative easy management of marmoset colonies. Table 1 provides an overview about species comparison between marmosets and the classically used Old World monkeys.

Figure 1. Common marmosets (Callithrix jacchus) are small non-human primates with a body weight of $350-450 \mathrm{~g}$. Adult marmoset at the facilities of the German Primate Center.

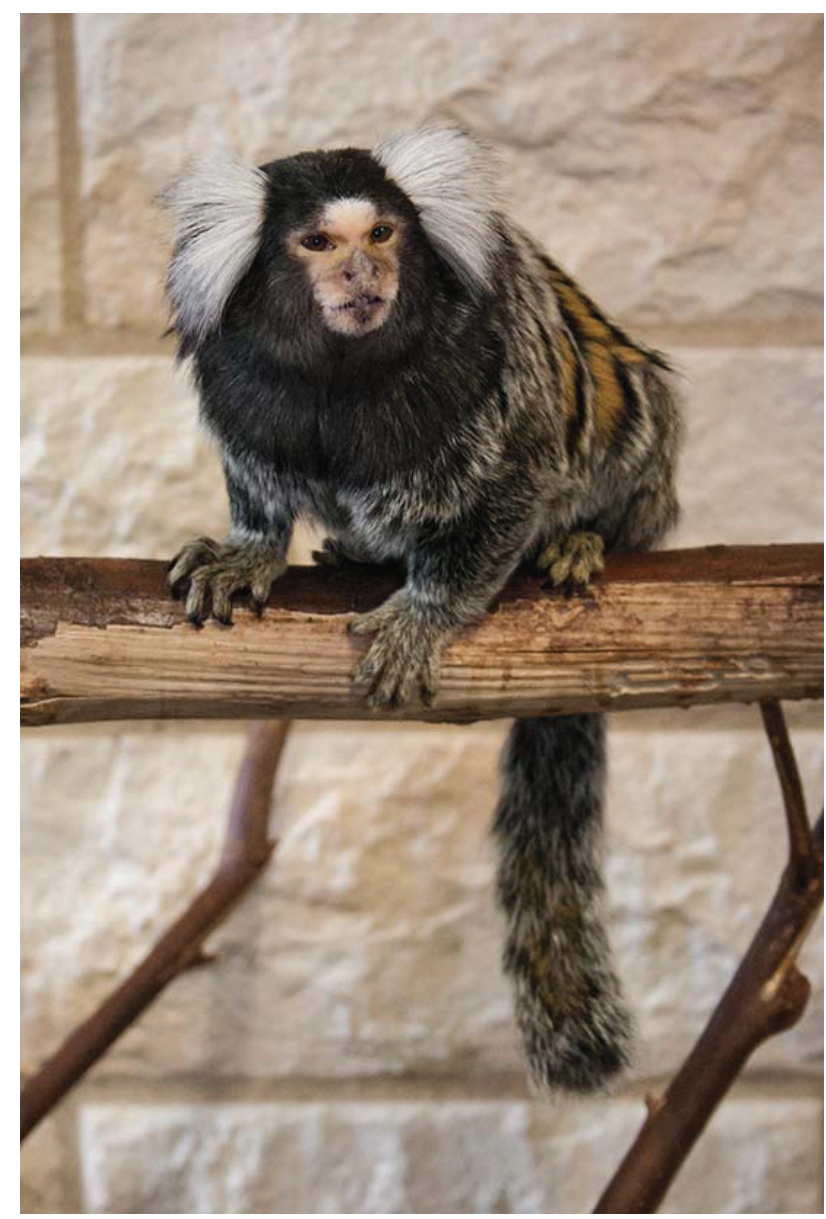


Marmosets are used as a non-rodent species in preclinical toxicology and safety studies. The close homology to humans makes the marmoset a suitable translational model for the human metabolism, enzyme structure and pharmacodynamic effects [3,6]. Furthermore, the high homology of marmoset and human immunological structures provides ground for predictive translational models of human diseases, e.g., to test new human specific biopharmaceuticals that do not find their target(s) in non-primate species $[7,8]$.

The use of marmosets as an animal model for human lung diseases is based on its human-like structure of the lung parenchyma and lung architecture [9]. Similar to humans and in contrast to the monopodial branching pattern in rodents, the marmoset's bronchial tree shows dichotomous branching [10,11]. Marmosets' alveolar size is comparable to other primates and monkey-specific islets of cartilage in the walls of bronchioles as well as highly alveolarized respiratory bronchioles can equally be found in the marmoset [9]. Furthermore, the marmoset's nasal cavity closely resembles the human nasal cavity's morphology, a requirement for translational inhalation studies with a high predictive power for the human situation [12].

A comparable distribution of goblet cells, Clara cells and mixed type secretory cells in the tracheobronchial tree of humans and marmosets is described, whereas there are more Clara cells and less goblet cells in the proximal and distal conducting airway epithelium of marmosets [13]. Another difference from the human situation is the distribution pattern of ciliated cells in the marmoset trachea with ciliated cells almost restricted to cartilage-free regions [14]. Furthermore, ultrastructural alterations of cilia of the respiratory epithelium are a common background finding in marmosets and should be taken into account when analyzing respective data from respiratory studies [15].

Figure 2. Bronchoscopy, a common respiratory technique, is feasible in marmosets. (A) The mouth of an adult anesthetized marmoset is opened with a laryngoscope. The bronchoscope is inserted into the trachea and advanced to the main bronchus under video control. Through the bronchoscope the lung can be partially flushed to receive BAL fluid. Bronchoscopic view of (B) trachea, (C) bifurcatio tracheae, (D) left and (E) right main bronchus. Note the early branching of the tracheal bronchus of the right cranial lobe.

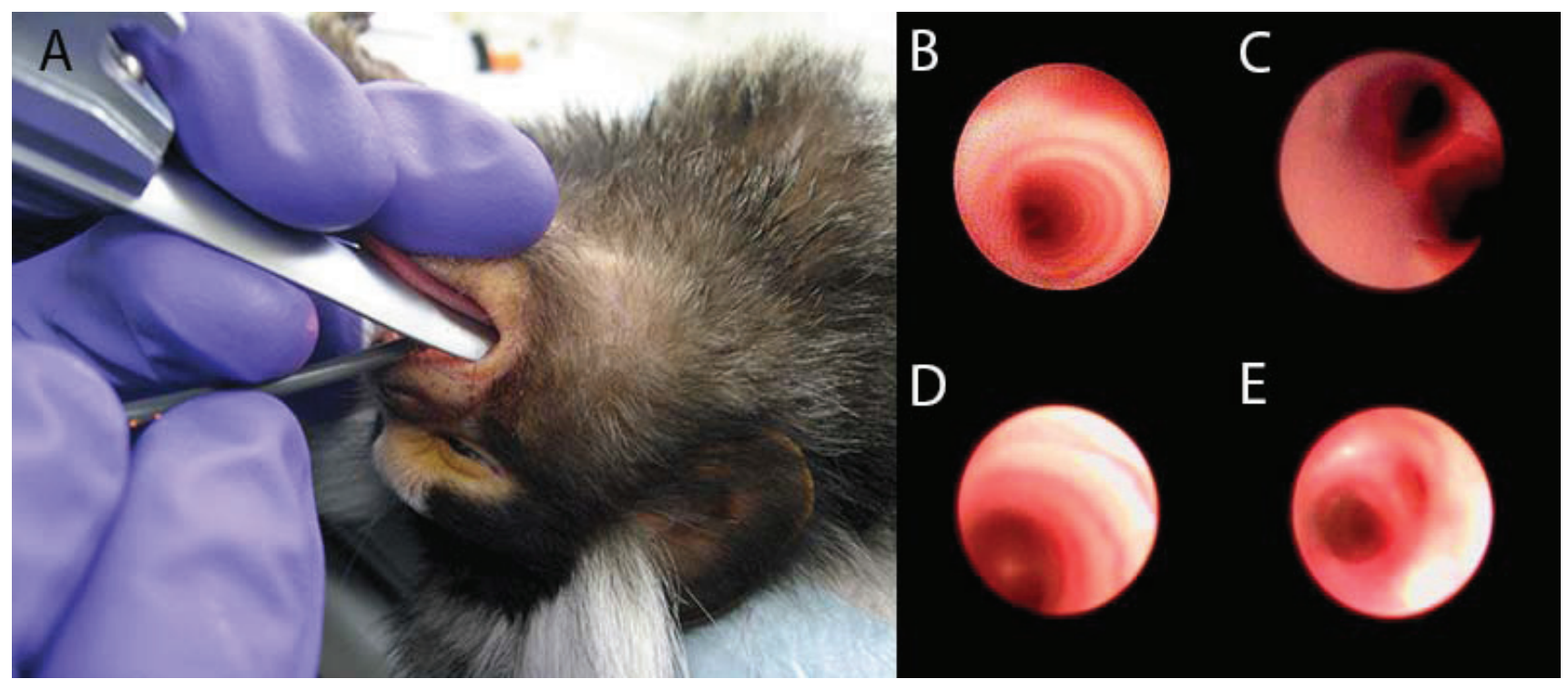


Similarities in human and marmoset neural airway responses, e.g., a comparable reaction towards electrical field stimulation, favor marmosets over rodent models in studies of airway pharmacology [16]. Yet, many aspects are still understudied and contrary results may cause uncertainty in the use of marmoset monkeys. For example, there are conflicting results regarding bronchoconstriction induced by the sensory neuron activator capsaicin in marmosets [16,17]. Despite these pitfalls, human-relevant bronchoconstrictors such as methacholine or histamine, the latter one which is inefficient in rodents, are potent in marmosets $[18,19]$. At the same time, serotonin, a powerful bronchoconstrictor in rodents, shows no effect in human and marmoset precision-cut lung slices [18], which underlines the importance of species homology for the predictive power of animal models. From the technical point of view, common respiratory techniques such as orotracheal intubation, bronchoscopy and bronchoalveolar lavage (BAL; uni- and bilateral) are well established in marmoset monkeys (Figure 2) [19-21].

\section{Models of Lung Inflammation}

Due to substantial similarities between the airway wall compartments of NHPs and humans, models of inflammatory lung diseases in nonhuman primates are expected to have advantages over classical rodent models that, to a high degree, lack those morphological similarities [12]. A marmoset model of bleomycin-induced pulmonary fibrosis has been reported to mimic human adult respiratory distress syndrome (ARDS) [22]. Transtracheal injection of bleomycin led to pulmonary fibrosis with elevated collagen deposition as well as increased lung lavage desmosine indicating lung elastin destruction [22]. Lung injury was expressed by initial edema, followed by an acute interstitial inflammation [22]. BAL showed a neutrophil dominated cell picture and lung function involved a decrease in lung compliance [22].

To model inflammatory features of human chronic obstructive pulmonary disease (COPD) and acute lung injury (ALI) a marmoset model of lipopolysaccharide (LPS)-induced acute lung inflammation was established recently [21]. Animals showed, temporarily, a distinct pulmonary inflammation [21]. Inflammation was characterized by an increase of pro-inflammatory cytokines such as tumor necrosis factor alpha (TNF- $\alpha$ ) and macrophage inflammatory protein-1 beta (MIP-1 $\beta$ ) [21]. High numbers of neutrophils were found in BAL fluid 18 hours post LPS application [21]. In a therapeutic intervention with orally administered anti-inflammatory drugs, dexamethasone and a phosphodiesterase-4 (PDE4) inhibitor (roflumilast), it was shown that lung inflammation could be suppressed significantly [21]. The model therefore provides an interesting approach to test new human specific anti-inflammatory drugs [21]. In addition to this, the same group of researchers characterized the model by comprehensive invasive lung function measurement [19]. Compared to naïve animals, airway hyperresponsiveness towards the bronchoconstrictor methacholine occurred post-LPS provocation [19]. Yet, the novel lung function device for marmoset monkeys, that allows inhalation of defined doses of provocative substances and simultaneous (real-time) recording of pulmonary data including key parameters such as lung resistance $\left(\mathrm{R}_{\mathrm{L}}\right)$ and dynamic compliance $\left(\mathrm{C}_{\mathrm{dyn}}\right)$ [19], makes the marmoset an attractive model for human airway diseases and its treatment. 


\section{Models of Viral Infection}

Marmosets have been utilized several times as a model for viral diseases [2,23]. While these models are not restricted to the respiratory tract, we in the following will focus on respiratory viral infection models. As a consequence of the SARS (Severe Acute Respiratory Syndrome) outbreak in 2002-2003, which killed almost 800 people [24], a marmoset model of the disease was developed that shares features with human SARS. Intratracheal application of SARS-associated coronavirus (SARS-CoV) induced an interstitial pneumonia attended by multinucleated syncytia, type 2 pneumocyte hyperplasia, and edema in the lung of infected animals [25]. Similar to human infection, extrapulmonary pathological findings included multifocal hepatitis in all, mild diffuse colitis in most, and mild multifocal lymphocytic myocarditis in some of the infected animals [25]. In addition to the clinical findings, the study showed that marmosets were susceptible to SARS-CoV infection by detection of viral RNA in lung tissue samples and localization of viral antigen in type I pneumocytes, mononuclear alveolar exudate, and multinucleated syncytial cells [25].

Marmosets were likewise susceptible to influenza A infection as shown in a study using the human pandemic virus A/California/07/2009 (H1N1pdm) [26]. The virus did not only replicate successfully in infected animals but was also transmitted to a naïve individual in one case [26]. Human-like influenza symptoms such as nasal secretion, sneezing and labored breathing accompanied infection in marmosets [26]. Tissue damage was demonstrated by elevated BAL fluid protein levels [26]. Proof of infection was obtained from recovery of viral RNA from BAL samples and nasal washout samples, using quantitative RT-PCR [26]. Interestingly, sequences of the viral genome isolated from the respiratory tract of infected marmosets revealed that the applied H1N1pdm swarm did only need minimal adaption to cause productive infection, indicating that the species barrier between humans and marmoset influenza infection is low [26]. Anti-H1N1pdm antibodies were detected in serum by hemagglutination inhibition assay [26]. The model seems to provide the exceptional opportunity to study influenza infection in a, for the human situation, highly homologous animal model [26].

Adenovirus infections are known to cause respiratory illness and are responsible for pneumonia outbreaks in humans [27]. Since human and nonhuman primate adenoviruses are closely related there is a risk of interspecies transmission [28,29]. Cross-species infection of marmosets with titi monkey (Callicebus cupreus) adenovirus (TMAdV) was shown [30]. Marmosets which were intranasally inoculated with TMAdV, developed clinical signs of acute mild respiratory illness [30]. A sustained infection was proven by positive TMAdV qPCR in nasal swab material and the detection of neutralizing antibody titers against the virus [30]. Animals recovered completely within two weeks [30]. Interestingly, TMAdV infection in titi monkeys produced a fulminant pneumonia with high mortality rates, whereas it caused a mild self-limiting respiratory infection in marmosets which resembled TMAdV infection in humans [30,31]. While the reason for this is, yet, unclear, Titi monkeys and marmosets belong to separate families [32] which could explain differences in clinical manifestations.

\section{Models of Bacterial Infection}

Several marmoset models of bacterial infection with respiratory implications are described with the objective to mimic the human situation and as alternatives to other nonhuman primates or rodent 
models. Legionnaires' disease, a severe form of pneumonia, is caused by Legionella pneumophila. The disease is transmitted by inhaling aerosolized contaminated water. Bacteria endure in alveolar macrophages where they cause inflammation [33,34]. Marmosets infected with small particle aerosols of L. pneumophila developed pulmonary lesions which resemble those of human Legionnaires' disease [35]. Likewise several days after infection, bronchopneumonia emerging from respiratory and terminal bronchioles and oedemas in the alveoli were observed [35]. Macrophage and polymorphonuclear leukocyte exudation into alveoli occurred and incorporated L. pneumophila were demonstrated by electron microscopy [36].

Melioidosis, induced by Burkholderia pseudomallei, is endemic and a considerable cause of mortality in Southeast Asia and northern Australia from where it is disseminating to other areas [37,38]. Treatment is difficult due to lack of vaccines and resistance to many antibiotics [39]. The first NHP animal model for studies of respiratory melioidosis was established in common marmosets by Nelson and colleagues [40]. Marmosets were highly susceptible to airborne infection with Burkholderia pseudomallei and developed human-like melioidosis including high mortality [40,41]. The rapidly progressive illness was associated with high fever, decreased activity and dyspnoea [40]. Abnormal liver function enzymes were observed as well as a blood neutrophil increase followed by neutropenia through neutrophil recruitment to the lungs [40]. Ultimately, bacteremia in the animals was observed in conjunction with an extensive bacterial load in the lung [40]. Pathological findings included necrotizing pneumonia, extensive haemorrhage and expanded alveolar oedema in the marmoset lungs [40]. Since melioidosis in the common marmoset resembled human Burkholderia pseudomallei infection this animal model is promising to study new therapeutic interventions against the disease [40]. Thus, it is not surprising, that the melioidosis model in marmosets was used to test phosphoantigen treatment towards a $\mathrm{T}$ cell subset $\left(\gamma 9^{+} \delta 2^{+}\right)$that is exclusively found in primate species $[42,43]$.

For several potentially fatal human infections including anthrax clinical trials in man are not possible which highlights the urgent need for convincing animal models to test antimicrobials and vaccines $[44,45]$. Especially for testing human anthrax vaccines, NHP models may have benefits over classical rodent models [46]. On the other hand, increased biosafety measures increase costs for housing and managing animals, which is particularly true for experiments with OWMs (e.g., rhesus and cynomolgus monkeys) [44]. Therefore, the marmoset monkey may serve as an attractive alternative to anthrax models in macaques. Aerosol infection with the Bacillus anthracis Ames strain in marmoset monkeys caused clinical signs of anthrax including dyspnoea, decreased stimuli response and disorientation. Half of the animals had to be put to sleep due to clinical signs of infection 40-140 $\mathrm{h}$ post-challenge [44]. Severely infected and therefore euthanized animals showed B. anthracis infection in several organs including the spleen and blood [44]. Histopathological results included pulmonary oedema and haemorrhage as it was also observed in NHP and humans as well as acute interstitial pneumonia [44]. Unlike in macaques or humans infection via aerosols caused no signs of meningitis in the common marmoset [44]. Ciprofloxacin, an antibiotic used to treat anthrax in humans [47], was used for therapeutic intervention in infected marmosets and proved to be sufficient to prevent mortality [48]. 
Limitations of mouse [49] and cynomolgus models of tuberculosis (TB) led to the development of a marmoset model of Mycobacterium tuberculosis complex infection [50]. Different strains of M. tuberculosis, partly emerging and drug resistant, were used to infect marmosets by aerosol exposure [50] which resulted in strain and dose dependent disease progression [50]. The higher virulence of an M. tuberculosis Beijing strain compared to the Euro-American lineage in other animal models of TB was reinforced in the marmoset [50]. In vivo computed tomography (CT) and positron emission tomography (PET) scans were used to quantify TB lung lesions over the course of infection [50]. Both abnormal lung density, as revealed by CT, and glycolytic activity visualized by 2-deoxy-2-[ $\left[{ }^{18}\right.$ F]fluoro-D-glucose (FDG) uptake, increased as M. tuberculosis infection progressed [50]. The highest bacterial load was found in the lung, spleen, liver, and lymph nodes of animals infected with M. tuberculosis Beijing strain K04 [50]. Infected marmosets exhibited pulmonary lesions and tuberculous pneumonia similar to human TB [50]. Furthermore, the study was interesting because it included chimeric marmoset twins to appraise reproducibility of infection and to assess strain-related differences. Twins infected with the same M. tuberculosis strains exhibited almost identical features of disease whereas twin animals exposed to different strains showed disparities specific for the group [50]. Animals infected with an ancient M. africanum-like strain for example showed a more extensive extrapulmonary disease and some marmosets infected with the Euro-American lineage developed cavitary disease which is associated with recidivism in humans [50,51]. In fact, marmoset models of TB infection with various $M$. tuberculosis strains include the different characteristics of human TB infection and thus may help to develop new therapeutic strategies to fight the disease.

The severe pulmonary form of leptospirosis (SPFL) associated with pulmonary hemorrhages and respiratory failure causes high mortality rates in humans and represents a particular aggressive form of the emerging zoonosis, which is induced by the spirochete Leptospira [52-54]. Marmosets were inoculated intra peritoneal with Leptospira interrogans serovar Copenhageni which was formerly isolated from a fatal human SPFL case [55]. Infection caused dehydration, weight loss and hepatic injury [55]. Bacteria were recovered from blood samples of infected animals and antibodies against the bacterium indicated seroconversion [55]. Gross pathology revealed hemorrhages on the pleural surface of the lung and histology showed intense intra-alveolar hemorrhages and thickened alveolar septa, caused by inflammatory cellular infiltrates as a response to infection on day 6, 9 and 12 post-inoculation [55]. It was possible to depict leptospiral antigens in the affected areas of lung parenchyma with immunofluorescence techniques [55]. In summary the disease elicited by experimental leptospirosis infection of marmosets with an SPFL-causing serovar resembled human courses of SPFL making the marmoset an attractive model species for human lung disease and pulmonary hemorrhages as a result of leptospirosis in particular [55].

\section{Further Models with Respiratory Implications}

For the reason that research on toxins needs reliable animal models as a surrogate for human trials [56] toxicological research and work safety is another field where marmoset models are useful. Sarin, known as a potent war gas, is an organophosphorus compound which leads to hyperstimulation of muscarinic and nicotinic receptors by inhibiting acetylcholinesterase (AChE) [57]. Beside its unacceptable use as a mass destruction agent, there is a high risk of occupational exposure to low 
levels of sarin, e.g., for personnel that has to destroy stockpiles or any kind of medical staff which comes into contact with intoxicated victims [58,59]. Long-term low-level exposure to sarin vapor was modeled in marmosets using a novel sensitive apparatus that facilitated vapor generation, exposure in a chamber, and analysis via gas chromatography [58]. Lowest observable effect levels (LOEL) were derived from sarin quantification in the blood [58]. Ascertained LOELs were much lower than previously assumed recommending occupational exposure limits to be re-examined [58].

Another toxin, Aflatoxin $\mathbf{B}_{1}\left(\mathrm{AFB}_{1}\right)$ is mainly known to promote hepatocellular carcinoma [60]. However, effects of this potent carcinogen are also observed in other parts of the body, such as the respiratory tract $[61,62]$. To investigate extra-hepatic sites of $\mathrm{AFB}_{1}$ accumulation and bioactivation in a primate model, marmosets were i.v. injected with radiolabelled ${ }^{3} \mathrm{H}-\mathrm{AFB}_{1}$ [63]. Cytochrome P-450-dependent bioactivation of $\mathrm{AFB}_{1}$ in epithelia of the nasal olfactory mucosa and the upper respiratory tract was observed in marmosets [63] indicating that these tissues were potentially susceptible for $\mathrm{AFB}_{1}$ related carcinogenicity [63].

Gene therapy is an approach to encounter genetic disorders through replacing deficient by functional genes. In marmoset monkeys, beside hematologic applications [64], gene transfers to the retina facilitated by adeno-associated virus vectors [65], was demonstrated. Furthermore, gene transfer in marmosets was studied to evaluate the potential of this species for gene therapies in cystic fibrosis [66]. Results indicated that marmoset lungs were successfully transduced in vivo using a VSV-G pseudo-typed HIV-based lentiviral vector [66]. Expression of the LacZ reporter gene was observed 7 days after gene transfer in deep lying conducting airway epithelial cells as well as alveolar epithelial cells [66]. Marmosets may represent a promising model species for gene therapy of human airway diseases such as cystic fibrosis [66]. Also, the high reproductive rate of this NHP species compared to OWMs should not be underestimated and contributes to the use of marmosets in stem cell research and gene therapy.

\section{Conclusions}

While there are promising translational animal models in marmoset monkeys, the species also has its limitations compared to OWMs. The limited blood sample volume or lower rates of human antibody cross-reactivity are potential drawbacks that need to be considered. However, due to its characteristics, the marmoset monkey is especially attractive when it comes to experiments and models with a high demand of animal numbers or high reproduction rates that are needed to foster a quick generation turnover rate, e.g., in stem cell or gene therapy. Also, the cost-benefit ratio is exceptionally good regarding preclinical studies with the additional advantage of using immunological identical twins for controlled study designs. The marmoset's close homology to humans is especially reflected in its lung architecture and airway branching pattern, which makes it a good model species for human lung diseases. Not only non-infectious, but also infectious disease models have been established in the marmoset with promising results. 
Table 1. Species comparison of advantages and disadvantages of macaque (rhesus, cynomolgus) and common marmoset animal models for respiratory diseases.

\begin{tabular}{|c|c|c|c|}
\hline & Macaques & Common marmosets & Reference \\
\hline \multicolumn{4}{|l|}{ Feature } \\
\hline Weight & $3.0-15.0 \mathrm{~kg}$ & $0.35-0.45 \mathrm{~kg}$ & {$[1]$} \\
\hline Sexual maturity & 41-66 months & 18-24 months & {$[1]$} \\
\hline Gestation length & 24 weeks & 21 weeks & [67] \\
\hline Interbirth interval & 12 months & 6 months & [67] \\
\hline Housing requirements (floor area $\times$ height) & $0.55 \mathrm{~m}^{2} \times 1.5 \mathrm{~m}$ & $2 \mathrm{~m}^{2} \times 1.8 \mathrm{~m}$ & $\begin{array}{c}\text { European } \\
\text { Directive } \\
\text { 2010/63/EU } \\
\end{array}$ \\
\hline Purchase price 2014 & $\sim 6,000-10,000 €$ & $\sim 3,000-5,000 €$ & p.c. \\
\hline $\begin{array}{l}\text { Material costs (esp. drug compound) for } \\
\text { pharmacology and toxicology studies }\end{array}$ & high & low & [3] \\
\hline $\begin{array}{l}\text { Hematopoietic chimerism of } \\
\text { dizygotic twins }\end{array}$ & no & yes & [2] \\
\hline $\begin{array}{l}\text { Inter-individual variation of } \\
\text { MHC class I and II loci }\end{array}$ & high & low & [1] \\
\hline $\begin{array}{l}\text { Identical aa residues in average for } \\
\text { immunity-related genes compared to human }\end{array}$ & $95 \pm 3.4$ & $87 \pm 5.4$ & [7] \\
\hline $\begin{array}{l}\text { Susceptible for viral and bacterial infection } \\
\text { with human-relevant pathogens }\end{array}$ & yes & yes & [23] \\
\hline Alveolar size & \multicolumn{2}{|c|}{ equal } & [9] \\
\hline Highly alveolarized respiratory bronchioles & yes & yes & [9] \\
\hline Bronchial branching pattern & \multicolumn{2}{|c|}{ dichotomous } & {$[10,11]$} \\
\hline Presence of Clara cells in the lung & $\begin{array}{c}\text { not in trachea and } \\
\text { major bronchi }\end{array}$ & in all airway segments & [13] \\
\hline Respiratory rate (under anesthesia) & $\sim 34$ breaths/min & $\sim 27$ breaths/min & [19] \\
\hline Latent Herpes Virus B infection & yes & no & {$[2]$} \\
\hline Wasting syndrome in captive colonies & absent & evident & [6] \\
\hline \multicolumn{4}{|l|}{ Methods } \\
\hline Handling & laborious & easy & [3] \\
\hline Complete clinical examination & feasible & feasible & [3] \\
\hline $\begin{array}{l}\text { Blood sample volume } \\
\text { (in vivo every two weeks) }\end{array}$ & $48 \mathrm{~mL}$ & $2.5 \mathrm{~mL}$ & $\begin{array}{c}\text { Society for } \\
\text { Laboratory } \\
\text { Animal Science }\end{array}$ \\
\hline Bronchoscopy & yes & yes & {$[21,68,69]$} \\
\hline BAL (uni- and bilateral) & yes & yes & {$[21,68,69]$} \\
\hline BAL flush volume & $10-15 \mathrm{~mL}$ & $2 \times 3 \mathrm{~mL}$ & {$[21,68,69]$} \\
\hline Lung function assessment & yes & yes & {$[19,68,69]$} \\
\hline $\begin{array}{l}\text { Cross-reactivity of } \\
\text { human-specific antibodies }\end{array}$ & frequent & limited & {$[70]$} \\
\hline
\end{tabular}




\section{Conflicts of Interest}

The authors declare no conflict of interest.

\section{References and Notes}

1. Abbott, D.H.; Barnett, D.K.; Colman, R.J.; Yamamoto, M.E.; Schultz-Darken, N.J. Aspects of common marmoset basic biology and life history important for biomedical research. Comp. Med. 2003, 53, 339-350.

2. Mansfield, K. Marmoset models commonly used in biomedical research. Comp. Med. 2003, 53, 383-392.

3. Orsi, A.; Rees, D.; Andreini, I.; Venturella, S.; Cinelli, S.; Oberto, G. Overview of the marmoset as a model in nonclinical development of pharmaceutical products. Regul. Toxicol. Pharmacol. 2011, 59, 19-27.

4. Sweeney, C.; Ward, J.; Vallender, E.J. Naturally occurring, physiologically normal, primate chimeras. Chimerism 2012, 3, 43-44.

5. Huff, J.L.; Barry, P.A. B-virus (cercopithecine herpesvirus 1) infection in humans and macaques: Potential for zoonotic disease. Emerg. Infect. Dis. 2003, 9, 246-250.

6. Smith, D.; Trennery, P.; Farningham, D.; Klapwijk, J. The selection of marmoset monkeys (callithrix jacchus) in pharmaceutical toxicology. Lab. Anim. 2001, 35, 117-130.

7. Kohu, K.; Yamabe, E.; Matsuzawa, A.; Onda, D.; Suemizu, H.; Sasaki, E.; Tanioka, Y.; Yagita, H.; Suzuki, D.; Kametani, Y.; et al. Comparison of 30 immunity-related genes from the common marmoset with orthologues from human and mouse. Tohoku J. Exp. Med. 2008, 215, 167-180.

8. 't Hart, B.A.; Abbott, D.H.; Nakamura, K.; Fuchs, E. The marmoset monkey: A multi-purpose preclinical and translational model of human biology and disease. Drug Discov. Today 2012, 17, 1160-1165.

9. Barbier, A.; Bachofen, H. The lung of the marmoset (callithrix jacchus): Ultrastructure and morphometric data. Respir. Physiol. 2000, 120, 167-177.

10. Plopper, C.G.; Hyde, D.M. The non-human primate as a model for studying copd and asthma. Pulm. Pharmacol. Ther. 2008, 21, 755-766.

11. Seidel, V. Morphological investigations on the lung of common marmosets (Callithrix jacchus) (in German). Doctoral Thesis, School of Veterinary Medicine, Hannover, Germany, 2012.

12. Wako, K.; Hiratsuka, H.; Katsuta, O.; Tsuchitani, M. Anatomical structure and surface epithelial distribution in the nasal cavity of the common cotton-eared marmoset (callithrix jacchus). Exp. Anim. 1999, 48, 31-36.

13. Seidel, V.; Hoffmann, R.; Braun, A.; Seehase, S.; Knauf, S.; Kaup, F.-J.; Bleyer, M. Distribution and morphology of clara cells in common marmosets (callithrix jacchus). J. Med. Primatol. 2013, $42,79-88$.

14. Hoffmann, R.; Braun, A.; Knauf, S.; Kaup, F.-J.; Bleyer, M. Distribution of ciliated epithelial cells in the trachea of common marmosets (callithrix jacchus). J. Med. Primatol. 2014, 43, 55-58. 
15. Hoffmann, R.M.; Kaup, F.-J.; Bleyer, M. Atypical cilia in the respiratory tract of common marmosets (callithrix jacchus) with and without concurrent lung disease. Exp. Lung Res. 2013, $39,410-414$.

16. Schlepütz, M.; Rieg, A.D.; Seehase, S.; Spillner, J.; Perez-Bouza, A.; Braunschweig, T.; Schroeder, T.; Bernau, M.; Lambermont, V.; Schlumbohm, C.; et al. Neurally mediated airway constriction in human and other species: A comparative study using precision-cut lung slices (PCLS). PLoS ONE 2012, 7, e47344.

17. Spina, D.; Matera, G.M.; Riccio, M.M.; Page, C.P. A comparison of sensory nerve function in human, guinea-pig, rabbit and marmoset airways. Life Sci. 1998, 63, 1629-1642.

18. Seehase, S.; Schlepütz, M.; Switalla, S.; Mätz-Rensing, K.; Kaup, F.-J.; Zöller, M.; Schlumbohm, C.; Fuchs, E.; Lauenstein, H.D.; Winkler, C.; et al. Bronchoconstriction in nonhuman primates: A species comparison. J. Appl. Physiol. 2011, 111, 791-798.

19. Curths, C.; Wichmann, J.; Dunker, S.; Windt, H.; Hoymann, H.G.; Lauenstein, H.D.; Hohlfeld, J.; Becker, T.; Kaup, F.-J.; Braun, A.; et al. Airway hyper-responsiveness in lipopolysaccharidechallenged common marmosets (callithrix jacchus). Clin. Sci. (Lond.) 2014, 126, 155-162.

20. Thomas, A.A.; Leach, M.C.; Flecknell, P.A. An alternative method of endotracheal intubation of common marmosets (callithrix jacchus). Lab. Anim. 2012, 46, 71-76.

21. Seehase, S.; Lauenstein, H.D.; Schlumbohm, C.; Switalla, S.; Neuhaus, V.; Forster, C.; Fieguth, H.G.; Pfennig, O.; Fuchs, E.; Kaup, F.-J.; et al. Lps-induced lung inflammation in marmoset monkeys-An acute model for anti-inflammatory drug testing. PLoS ONE 2012, 7, e43709.

22. Idell, S.; Thrall, R.S.; Maunder, R.; Martin, T.R.; McLarty, J.; Scott, M.; Starcher, B.C. Bronchoalveolar lavage desmosine in bleomycin-induced lung injury in marmosets and patients with adult respiratory distress syndrome. Exp. Lung Res. 1989, 15, 739-753.

23. Carrion, R., Jr.; Patterson, J.L. An animal model that reflects human disease: The common marmoset (callithrix jacchus). Curr. Opin. Virol. 2012, 2, 357-362.

24. Christian, M.D.; Poutanen, S.M.; Loutfy, M.R.; Muller, M.P.; Low, D.E. Severe acute respiratory syndrome. Clin. Infect. Dis. 2004, 38, 1420-1427.

25. Greenough, T.C.; Carville, A.; Coderre, J.; Somasundaran, M.; Sullivan, J.L.; Luzuriaga, K.; Mansfield, K. Pneumonitis and multi-organ system disease in common marmosets (callithrix jacchus) infected with the severe acute respiratory syndrome-associated coronavirus. Am. J. Pathol. 2005, 167, 455-463.

26. Moncla, L.H.; Ross, T.M.; Dinis, J.M.; Weinfurter, J.T.; Mortimer, T.D.; Schultz-Darken, N.; Brunner, K.; Capuano, S.V., 3rd; Boettcher, C.; Post, J.; et al. A novel nonhuman primate model for influenza transmission. PLoS ONE 2013, 8, e78750.

27. Tsou, T.P.; Tan, B.F.; Chang, H.Y.; Chen, W.C.; Huang, Y.P.; Lai, C.Y.; Chao, Y.N.; Wei, S.H.; Hung, M.N.; Hsu, L.C.; et al. Community outbreak of adenovirus, Taiwan, 2011. Emerg. Infect. Dis. 2012, 18, 1825-1832. 
28. Wevers, D.; Metzger, S.; Babweteera, F.; Bieberbach, M.; Boesch, C.; Cameron, K.; Couacy-Hymann, E.; Cranfield, M.; Gray, M.; Harris, L.A.; et al. Novel adenoviruses in wild primates: A high level of genetic diversity and evidence of zoonotic transmissions. J. Virol. 2011, 85, 10774-10784.

29. Ersching, J.; Hernandez, M.I.; Cezarotto, F.S.; Ferreira, J.D.; Martins, A.B.; Switzer, W.M.; Xiang, Z.; Ertl, H.C.; Zanetti, C.R.; Pinto, A.R. Neutralizing antibodies to human and simian adenoviruses in humans and new-world monkeys. Virology 2010, 407, 1-6.

30. Yu, G.; Yagi, S.; Carrion, R., Jr.; Chen, E.C.; Liu, M.; Brasky, K.M.; Lanford, R.E.; Kelly, K.R.; Bales, K.L.; Schnurr, D.P.; et al. Experimental cross-species infection of common marmosets by titi monkey adenovirus. PLoS One 2013, 8, e68558.

31. Chen, E.C.; Yagi, S.; Kelly, K.R.; Mendoza, S.P.; Tarara, R.P.; Canfield, D.R.; Maninger, N.; Rosenthal, A.; Spinner, A.; Bales, K.L.; et al. Cross-species transmission of a novel adenovirus associated with a fulminant pneumonia outbreak in a new world monkey colony. PLoS Pathog. 2011, 7, e1002155.

32. Perelman, P.; Johnson, W.E.; Roos, C.; Seuanez, H.N.; Horvath, J.E.; Moreira, M.A.; Kessing, B.; Pontius, J.; Roelke, M.; Rumpler, Y.; et al. A molecular phylogeny of living primates. PLoS Genet. 2011, 7, e1001342.

33. Fields, B.S.; Benson, R.F.; Besser, R.E. Legionella and legionnaires' disease: 25 years of investigation. Clin. Microbiol. Rev. 2002, 15, 506-526.

34. Xu, L.; Luo, Z.Q. Cell biology of infection by legionella pneumophila. Microbes Infect. 2013, 15, 157-167.

35. Baskerville, A.; Fitzgeorge, R.B.; Broster, M.; Hambleton, P. Histopathology of experimental legionnaires' disease in guinea pigs, rhesus monkeys and marmosets. J. Pathol. 1983, 139, 349-362.

36. Baskerville, A.; Dowsett, A.B.; Fitzgeorge, R.B.; Hambleton, P.; Broster, M. Ultrastructure of pulmonary alveoli and macrophages in experimental Legionnaires' disease. J. Pathol. 1983, 140, 77-90.

37. Cheng, A.C.; Currie, B.J. Melioidosis: Epidemiology, pathophysiology, and management. Clin. Microbiol. Rev. 2005, 18, 383-416.

38. Currie, B.J.; Dance, D.A.; Cheng, A.C. The global distribution of burkholderia pseudomallei and melioidosis: An update. Trans. R. Soc. Trop. Med. Hyg. 2008, 102(Suppl 1), S1-S4.

39. Choh, L.C.; Ong, G.H.; Vellasamy, K.M.; Kalaiselvam, K.; Kang, W.T.; Al-Maleki, A.R.; Mariappan, V.; Vadivelu, J. Burkholderia vaccines: Are we moving forward? Front. Cell. Infect. Microbiol. 2013, 3, 5 .

40. Nelson, M.; Dean, R.E.; Salguero, F.J.; Taylor, C.; Pearce, P.C.; Simpson, A.J.; Lever, M.S. Development of an acute model of inhalational melioidosis in the common marmoset (callithrix jacchus). Int. J. Exp. Pathol. 2011, 92, 428-435.

41. White, N.J. Melioidosis. Lancet 2003, 361, 1715-1722.

42. Rowland, C.A.; Laws, T.R.; Oyston, P.C. An assessment of common marmoset (callithrix jacchus) gamma9(+) t cells and their response to phosphoantigen in vitro. Cell. Immunol. 2012, 280, $132-137$. 
43. Laws, T.R.; Nelson, M.; Bonnafous, C.; Sicard, H.; Taylor, C.; Salguero, F.J.; Atkins, T.P.; Oyston, P.C.; Rowland, C.A. In vivo manipulation of gamma9(+) t cells in the common marmoset (callithrix jacchus) with phosphoantigen and effect on the progression of respiratory melioidosis. PLoS One 2013, 8, e74789.

44. Lever, M.S.; Stagg, A.J.; Nelson, M.; Pearce, P.; Stevens, D.J.; Scott, E.A.; Simpson, A.J.; Fulop, M.J. Experimental respiratory anthrax infection in the common marmoset (callithrix jacchus). Int. J. Exp. Pathol. 2008, 89, 171-179.

45. Food Drug Administration, H.H.S. New drug and biological drug products; evidence needed to demonstrate effectiveness of new drugs when human efficacy studies are not ethical or feasible. Final rule. Fed. Regist. 2002, 67, 37988-37998.

46. Fellows, P.F.; Linscott, M.K.; Ivins, B.E.; Pitt, M.L.; Rossi, C.A.; Gibbs, P.H.; Friedlander, A.M. Efficacy of a human anthrax vaccine in guinea pigs, rabbits, and rhesus macaques against challenge by bacillus anthracis isolates of diverse geographical origin. Vaccine 2001, 19, 3241-3247.

47. Bell, D.M.; Kozarsky, P.E.; Stephens, D.S. Clinical issues in the prophylaxis, diagnosis, and treatment of anthrax. Emerg. Infect. Dis. 2002, 8, 222-225.

48. Nelson, M.; Stagg, A.J.; Stevens, D.J.; Brown, M.A.; Pearce, P.C.; Simpson, A.J.; Lever, M.S. Post-exposure therapy of inhalational anthrax in the common marmoset. Int. J. Antimicrob. Agents 2011, 38, 60-64.

49. Mitchison, D.A.; Chang, K.C. Experimental models of tuberculosis: Can we trust the mouse? Am. J. Respir. Crit. Care Med. 2009, 180, 201-202.

50. Via, L.E.; Weiner, D.M.; Schimel, D.; Lin, P.L.; Dayao, E.; Tankersley, S.L.; Cai, Y.; Coleman, M.T.; Tomko, J.; Paripati, P.; et al. Differential virulence and disease progression following mycobacterium tuberculosis complex infection of the common marmoset (callithrix jacchus). Infect. Immun. 2013, 81, 2909-2919.

51. Hamilton, C.D.; Stout, J.E.; Goodman, P.C.; Mosher, A.; Menzies, R.; Schluger, N.W.; Khan, A.; Johnson, J.L.; Vernon, A.N.; Tuberculosis Trials, C. The value of end-of-treatment chest radiograph in predicting pulmonary tuberculosis relapse. Int. J. Tuberc. Lung Dis. 2008, 12, 1059-1064.

52. Helmerhorst, H.J.; van Tol, E.N.; Tuinman, P.R.; de Vries, P.J.; Hartskeerl, R.A.; Grobusch, M.P.; Hovius, J.W. Severe pulmonary manifestation of leptospirosis. Neth. J. Med. 2012, 70, 215-221.

53. Silva, J.J.; Dalston, M.O.; Carvalho, J.E.; Setubal, S.; Oliveira, J.M.; Pereira, M.M. Clinicopathological and immunohistochemical features of the severe pulmonary form of leptospirosis. Rev. Soc. Bras. Med. Trop. 2002, 35, 395-399.

54. Gouveia, E.L.; Metcalfe, J.; de Carvalho, A.L.; Aires, T.S.; Villasboas-Bisneto, J.C.; Queirroz, A.; Santos, A.C.; Salgado, K.; Reis, M.G.; Ko, A.I. Leptospirosis-associated severe pulmonary hemorrhagic syndrome, salvador, brazil. Emerg. Infect. Dis. 2008, 14, 505-508.

55. Pereira, M.M.; Da Silva, J.J.; Pinto, M.A.; Da Silva, M.F.; Machado, M.P.; Lenzi, H.L.; Marchevsky, R.S. Experimental leptospirosis in marmoset monkeys (callithrix jacchus): A new model for studies of severe pulmonary leptospirosis. Am. J. Trop. Med. Hyg. 2005, 72, 13-20.

56. Levy, A.; Cohen, G.; Gilat, E.; Kapon, J.; Dachir, S.; Abraham, S.; Herskovitz, M.; Teitelbaum, Z.; Raveh, L. Extrapolating from animal studies to the efficacy in humans of a pretreatment combination against organophosphate poisoning. Arch. Toxicol. 2007, 81, 353-359. 
57. Antonijevic, B.; Stojiljkovic, M.P. Unequal efficacy of pyridinium oximes in acute organophosphate poisoning. Clin. Med. Res. 2007, 5, 71-82.

58. Van Helden, H.P.; Trap, H.C.; Oostdijk, J.P.; Kuijpers, W.C.; Langenberg, J.P.; Benschop, H.P. Long-term, low-level exposure of guinea pigs and marmosets to sarin vapor in air: Lowest observable effect level. Toxicol. Appl. Pharmacol. 2003, 189, 170-179.

59. Nozaki, H.; Hori, S.; Shinozawa, Y.; Fujishima, S.; Takuma, K.; Sagoh, M.; Kimura, H.; Ohki, T.; Suzuki, M.; Aikawa, N. Secondary exposure of medical staff to sarin vapor in the emergency room. Intensive Care Med. 1995, 21, 1032-1035.

60. Matsuda, Y.; Wakai, T.; Kubota, M.; Osawa, M.; Sanpei, A.; Fujimaki, S. Mycotoxins are conventional and novel risk biomarkers for hepatocellular carcinoma. World J. Gastroenterol. 2013, 19, 2587-2590.

61. van Vleet, T.R.; Watterson, T.L.; Klein, P.J.; Coulombe, R.A., Jr. Aflatoxin b1 alters the expression of p53 in cytochrome p450-expressing human lung cells. Toxicol. Sci. 2006, 89, 399-407.

62. Wilson, D.W.; Ball, R.W.; Coulombe, R.A., Jr. Comparative action of aflatoxin b1 in mammalian airway epithelium. Cancer Res. 1990, 50, 2493-2498.

63. Larsson, P.; Tjalve, H. Distribution and metabolism of aflatoxin b1 in the marmoset monkey (callithrix jacchus). Carcinogenesis 1993, 14, 1-6.

64. Hibino, H.; Tani, K.; Ikebuchi, K.; Wu, M.S.; Sugiyama, H.; Nakazaki, Y.; Tanabe, T.; Takahashi, S.; Tojo, A.; Suzuki, S.; et al. The common marmoset as a target preclinical primate model for cytokine and gene therapy studies. Blood 1999, 93, 2839-2848.

65. Ivanova, E.; Hwang, G.S.; Pan, Z.H.; Troilo, D. Evaluation of aav-mediated expression of chop2-gfp in the marmoset retina. Invest. Ophthalmol. Vis. Sci. 2010, 51, 5288-5296.

66. Farrow, N.; Miller, D.; Cmielewski, P.; Donnelley, M.; Bright, R.; Parsons, D.W. Airway gene transfer in a non-human primate: Lentiviral gene expression in marmoset lungs. Sci. Rep. 2013, 3, 1287.

67. Abee, C.R.; Mansfield, K. Nonhuman Primates in Biomedical Research, 2nd ed.; Elsevier: London, UK, 2012; p. 201.

68. Iwashita, K.; Kawasaki, H.; Sawada, M.; In, M.; Mataki, Y.; Kuwabara, T. Shortening of the induction period of allergic asthma in cynomolgus monkeys by ascaris suum and house dust mite. J. Pharmacol. Sci. 2008, 106, 92-99.

69. Schelegle, E.S.; Gershwin, L.J.; Miller, L.A.; Fanucchi, M.V.; van Winkle, L.S.; Gerriets, J.P.; Walby, W.F.; Omlor, A.M.; Buckpitt, A.R.; Tarkington, B.K.; et al. Allergic asthma induced in rhesus monkeys by house dust mite (dermatophagoides farinae). Am. J. Pathol. 2001, 158, 333-341.

70. Jagessar, S.A.; Vierboom, M.; Blezer, E.L.; Bauer, J.; Hart, B.A.; Kap, Y.S. Overview of models, methods, and reagents developed for translational autoimmunity research in the common marmoset (callithrix jacchus). Exp. Anim. 2013, 62, 159-171.

(C) 2014 by the authors; licensee MDPI, Basel, Switzerland. This article is an open access article distributed under the terms and conditions of the Creative Commons Attribution license (http://creativecommons.org/licenses/by/3.0/). 